\title{
Successful Removal of Foreign Body Bronchus Using C-arm-guided Insertion of Fogarty Catheter through Plastic Bead
}

\author{
Ravindra Ganuji Wankhede, Gaurab Maitra, Subhabrata Pal, Anirban Ghoshal, Soumen Mitra ${ }^{1}$ \\ Departments of Anaesthesia and 'Pediatric Surgery, Apollo Gleneagles Hospital, Kolkata, West Bengal, India
}

\section{Abstract}

Foreign body aspiration is still a cause of significant morbidity in children. Complications occur due to difficulty in diagnosis and treatment. An eight-year-old child presented with a history of recurrent cough for 3 days. Rigid bronchoscopy under general anesthesia revealed plastic bead occupying right main bronchus. Removal with grasping forceps failed for several times due to spherical, smooth, and large bead. Finally, Fogarty catheter was passed through bead under C-arm guidance and successfully removed.

Keywords: C-arm, Fogarty catheter, foreign body bronchus

\section{INTRODUCTION}

Children under 3 years are most susceptible for aspiration. Beads are difficult to remove due to smooth and spherical shape which cannot be broken into pieces and difficult to hold with forceps. Fogarty catheter has been used between foreign body (FB) and bronchus wall as well as through FB for removal. We report the use of $\mathrm{C}$-arm-guided Fogarty catheter insertion through bead for removal from bronchus in a child.

\section{Case Report}

An eight-year-old healthy child presented with a complaint of recurrent cough for 3 days with a history of child playing with beads. On examination, there was decreased air entry on right side. X-ray showed FB in the right main bronchus [Figure 1]. Apart from high white cell count, blood reports were normal, and rigid bronchoscopy was planned. Child was kept adequately fasting. Under standard monitoring, anesthesia induced with injection glycopyrrolate, ketamine, propofol, and atracurium with controlled ventilation. Rigid ventilating bronchoscope confirmed plastic bead in the right main bronchus. The left side was examined before intervention. Removal attempted using forceps, which failed due to spherical shape, large size, and smooth surface [Figure 2]. Next, Fogarty

\begin{tabular}{|l|l|}
\hline \multicolumn{2}{|c|}{ Access this article online } \\
\hline Quick Response Code: & Website: \\
\hline & www.ijccm.org \\
\hline & \\
\hline
\end{tabular}

catheter tried to insert between bronchus and FB, which also failed due to snuggly fitting bead. Finally, 4F Fogarty catheter passed through the bead, balloon was inflated and while trying to pull FB, resulted in rupture of balloon. On second attempt, new Fogarty catheter was inserted with the help of C-arm to confirm that Fogarty catheter is adequately passed beyond bead, there is no overinflation of balloon and withdrawal was done slowly. Bead was removed successfully as a unit with Fogarty catheter and scope together [Figure 3].

Oxygenation was well maintained. At the end of the procedure, $\mathrm{CO}_{2}$ was adequately washed out, and anesthesia was reversed. The dose of steroid was given to avoid airway edema.

\section{Discussion}

FB aspiration is leading cause of accidental death in young children below 3 years of age. ${ }^{[1,2]}$ Organic material is most common FB and around $88 \%$ occupied in bronchial tree. ${ }^{[1]}$

Address for correspondence: Dr. Ravindra Ganuji Wankhede, Department of Anaesthesia, Apollo Gleneagles Hospitals, Kolkata, West Bengal, India. E-mail: ravigwankhede@gmail.com

This is an open access article distributed under the terms of the Creative Commons Attribution-NonCommercial-ShareAlike 3.0 License, which allows others to remix, tweak, and build upon the work non-commercially, as long as the author is credited and the new creations are licensed under the identical terms.

For reprints contact: reprints@medknow.com

How to cite this article: Wankhede RG, Maitra G, Pal S, Ghoshal A, Mitra S. Successful removal of foreign body bronchus using $\mathrm{C}$-arm-guided insertion of fogarty catheter through plastic bead. Indian J Crit Care Med 2017;21:96-8. 


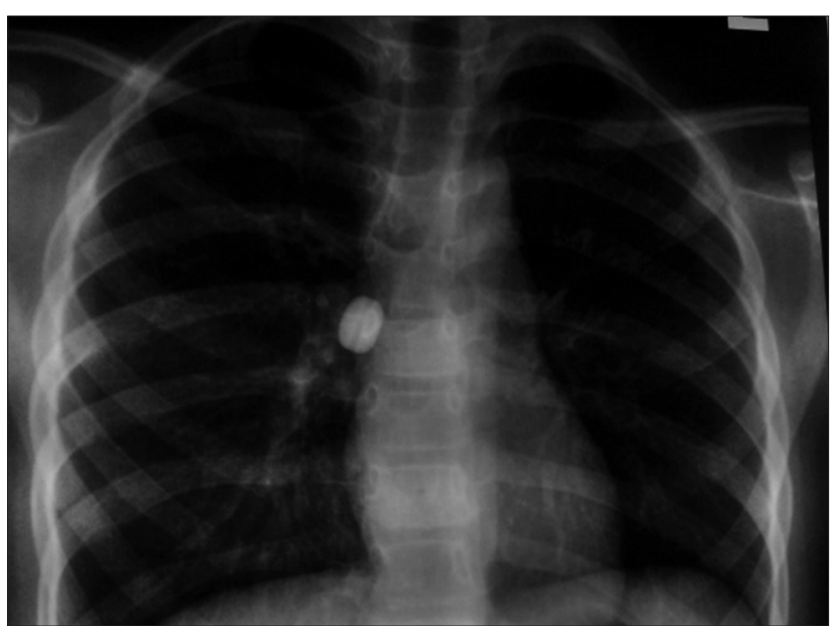

Figure 1: X-ray of the chest shows foreign body in right bronchus.

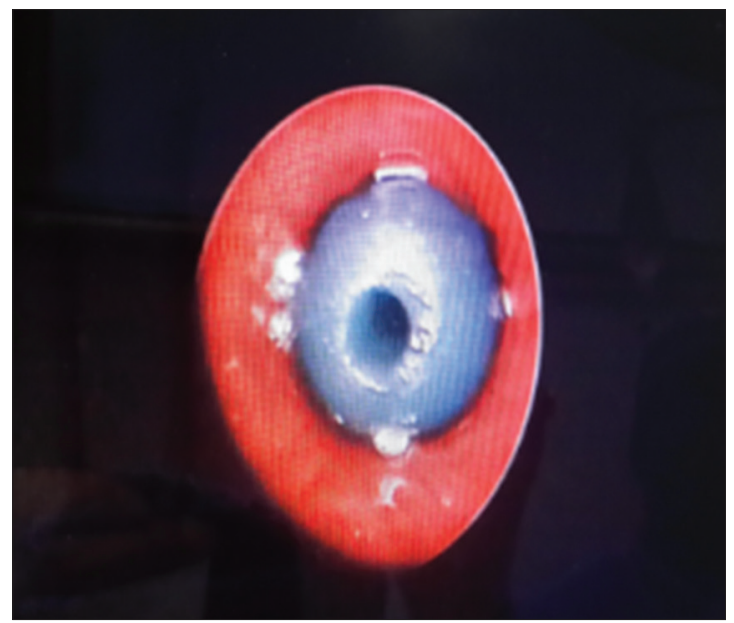

Figure 2: Endoscopic view shows spherical, smooth, and snugly occupied right bronchus with bead.

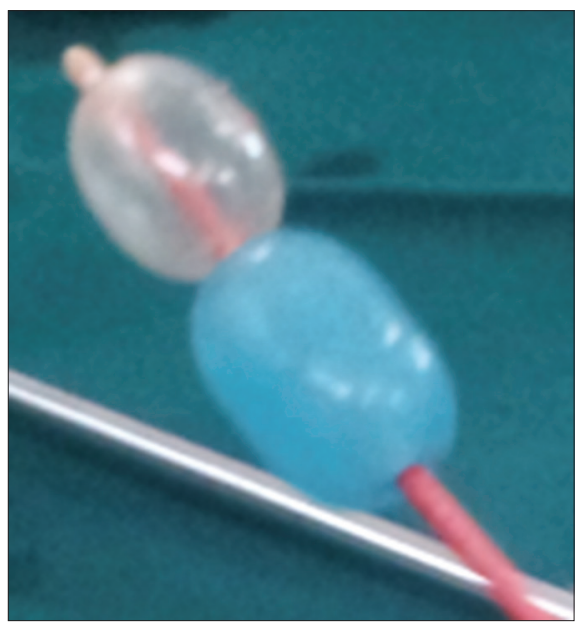

Figure 3: Foreign body removed with Fogarty catheter through bead.

Clinically, they may present with cough, unilateral wheeze, and decreased breath sounds which seen in only $65 \%$ patients. Any patient with a positive history, classical symptoms, or radiological evidence needs intervention. X-ray is the choice of investigation.

Preoperative preparation is crucial. Proper sizes bronchoscopes, expert clinicians, and all necessary preparations for open surgery are essential. Nil by mouth is preferred whenever possible. ${ }^{[1]}$ Oxygenation is usually well maintained with ventilating bronchoscope, but ventilation is inadequate due to leak. ${ }^{[3]}$ Premedication with glycopyrrolate is desirable. ${ }^{[4]}$ Occasionally, FB removal is difficult due to large size, spherical, or sharp objects. ${ }^{[5]}$ Breaking FB and tracheotomy may be necessary to remove large FB. Airway trauma should be avoided.

Large bronchoscope size, prolong procedure, and repeated attempt can lead to airway edema.

Fogarty catheter is used mainly to remove distal FB, or along with grasping forceps when FB is large where catheter is passed between FB and bronchus. ${ }^{[6]}$ In FB such as bead, Fogarty catheter has been used through the bead to extract it. ${ }^{[7]}$ Fogarty catheter can lead to complications such as rupture and embolism mainly due to blind procedure and excessive force applied during withdrawal. ${ }^{[7]}$

While there is no ideal anesthesia technique and no outcome difference between spontaneous or positive pressure ventilation, controlled ventilation is more effective..$^{[1,8]}$ In our case, it was difficult to hold bead due to large size and smooth surface. There was also risk of dislodgment during removal, which can go to either bronchus. Passing of Fogarty catheter between FB and bronchus was difficult. Fogarty catheter balloon got ruptured during withdrawal, which could be due to excessive force or overinflation. On the second attempt, new catheter passed under $\mathrm{C}$-arm guidance to make sure that balloon is passed beyond bead, balloon was inflated with a smaller amount, and withdrawal was done under $\mathrm{C}$-arm guidance. If endoscopic removal fails, then open airway surgery was only option, which carries high risk.

\section{Conclusion}

Airway FB removal can be a challenging task. It should be done in a tertiary care center where all possible interventions can be carried out. Careful diagnosis, planning, availability of resources, and expert clinician are essential for safe management.

\section{Financial support and sponsorship \\ Nil.}

\section{Conflicts of interest}

There are no conflicts of interest.

\section{REFERENCES}

1. Fidkowski CW, Zheng H, Firth PG. The anesthetic considerations of tracheobronchial foreign bodies in children: A literature review of 12,979 cases. Anesth Analg 2010;111:1016-25.

2. Foltran F, Ballali S, Passali FM, Kern E, Morra B, Passali GC, et al. Foreign bodies in the airways: A meta-analysis of published papers. Int J Pediatr Otorhinolaryngol 2012;76 Supp1 1:S12-9. 
3. Slinger PD, Campos JH. Anesthesia for thoracic surgery. In: Miller RD, editor. Miller's Anesthesia. $7^{\text {th }}$ ed. California: Churchill Livingstone; 2010. p. 1819-87.

4. Feldman MA, Patel A. Anesthesia for eye, ear, nose and throat surgery. In: Miller RD, editor. Miller's Anesthesia. $7^{\text {th }}$ ed. California: Churchill Livingstone; 2010. p. 2357-88.

5. Good GM, Deutsch ES. Method for removing endobronchial beads. Ann Otol Rhinol Laryngol 1998;107:291-2.
6. Lim SH, Lee DK, Lee JY. Bronchial foreign body removal under general anesthesia with a modified port, a fogarty balloon catheter and a grasping forceps. Korean J Anesthesiol 2011;61:177-9.

7. Elsharkawy H, Abd-Elsayed AA, Karroum R. Management challenges in the passing-through technique using a fogarty catheter to remove an endobronchial foreign body from an infant. Ochsner J 2015;15:110-3.

8. Kosloske AM. Bronchoscopic extraction of aspirated foreign bodies in children. Am J Dis Child 1982;136:924-7. 